\title{
Novel Analgesic Triglycerides from Cultures of Agaricus macrosporus and Other Basidiomycetes as Selective Inhibitors of Neurolysin
}

\author{
Marc Stadler, Veronika Hellwig ${ }^{\dagger}$, Anke Mayer-Bartschmid, Dirk Denzer, \\ Burkhard Wiese, Nils Burkhardt
}

Received: July 4, 2005 / Accepted: November 22, 2005

(C) Japan Antibiotics Research Association

\begin{abstract}
The agaricoglycerides are a new class of fungal secondary metabolites that constitute esters of chlorinated 4-hydroxy benzoic acid and glycerol. They are produced in cultures of the edible mushroom, Agaricus macrosporus, and several other basidiomycetes of the genera Agaricus, Hypholoma, Psathyrella and Stropharia. The main active principle, agaricoglyceride A, showed strong activities against neurolysin, a protease involved in the regulation of dynorphin and neurotensin metabolism $\left(\mathrm{IC}_{50}=200 \mathrm{nM}\right)$, and even exhibited moderate analgesic in vivo activities in an in vivo model. Agaricoglyceride monoacetates $\left(\mathrm{IC}_{50}=50 \mathrm{nM}\right)$ showed even stronger in vitro activities. Several further co-metabolites with weaker or lacking bioactivities were also obtained and characterized. Among those were further agaricoglyceride derivatives, as well as further chlorinated phenol derivatives such as the new compound, agaricic ester. The characteristics of the producer organisms, the isolation of bioactive metabolites from cultures of $A$. macrosporus, their biological activities, and preliminary results on their occurrence in basidiomycetes, are described.
\end{abstract}

Keywords agaricoglycerides, pain, fermentation, fungi, in vivo activity

M. Stadler (Corresponding author), V. Hellwig, A. MayerBartschmid, D. Denzer, N. Burkhardt: Bayer Health Care, Pharma Division, Research Center Wuppertal, Bldg. 0452, P.O.B. 1017 09, D-42096 Wuppertal, Germany.

E-mail: marc.stadler@t-online.de

\section{Introduction}

Neurolysin (EC 3.4.24.16) is a zinc metalloprotease that inactivates particular biologically active peptides, such as neurotensin and dynorphin A, by specific cleavage [1]. Whereas the kappa-opioid receptor agonist dynorphin A is a well-known and obvious endogenous pain-relieving peptide, neurotensin has been reported to have analgesic properties when applied centrally in animal models [2]. Therefore, neurolysin inhibitors are likely to enhance the analgesic properties of neurotensin and/or dynorphin A by inhibiting cleavage and inactivation of these peptides. Accordingly, selective inhibitors of neurolysin are likely to emphasize the analgesic effects of the aforementioned peptides, which accumulate if their inactivation is prevented. Hence, neurolysin inhibitors appear useful alternatives to complement or substitute therapy with morphine and other opiates in the treatment of severe pain. However, only few specific inhibitors of this target have hitherto been found. Those mostly constituted peptides [3 5], and otherwise there are few examples for nonpeptidic inhibitors of this enzyme, such as particular hydroxamates [6]. Therefore, a high throughput screening (HTS) for novel selective non-peptidic neurolysin inhibitors

B. Wiese: Bayer CropScience AG, RD-R-Discovery Chemistry, Monheim, Germany.

${ }^{\dagger}$ Present address: Institute for Coastal Research, Marine Bioanalytical Chemistry, GKSS-Forschungszentrum Geesthacht GmbH, Max-Planck-Str. 1, D-21502 Geesthacht/Germany 
<smiles>[R]c1cc(C(=O)OC(COC(=O)c2cc(Cl)c(O)c(Cl)c2)COC(=O)c2cc(Cl)c(O)c(Cl)c2)cc(Cl)c1O</smiles>

1: $(\mathrm{R}=\mathrm{Cl}) ; 2:(\mathrm{R}=\mathrm{H})$<smiles>COc1c(Cl)cc(CO)cc1Cl</smiles>

5<smiles>CC(=O)Oc1c(Cl)cc(C(=O)OCC(COC(=O)c2cc(Cl)c(O)c(Cl)c2)OC(=O)c2cc(Cl)c(O)c(Cl)c2)cc1Cl</smiles>

$1 a$<smiles>COc1c(Cl)cc(C(=O)O)cc1Cl</smiles>

6<smiles>[R]OC(COC(=O)c1cc(Cl)c(O)c(Cl)c1)COC(=O)c1cc(Cl)c(O)c(Cl)c1</smiles>

3: $(R=H) ; 4:(R=A c e t y l)$<smiles>CC(=O)Oc1c(Cl)cc(C(=O)OC(COC(=O)c2cc(Cl)c(O)c(Cl)c2)COC(=O)c2cc(Cl)c(O)c(Cl)c2)cc1Cl</smiles>

1b<smiles>COc1c(Cl)cc(COC(=O)c2cc(Cl)c(O)c(Cl)c2)cc1Cl</smiles>

7

Fig. 1 Chemical structures of metabolites isolated from Agaricus macrosporus.

1: Agaricoglyceride A; 2: Agaricoglyceride $B ; \mathbf{1 a} / \mathbf{b}$ : Monoacetyl-agaricoglycerides $A$ (isolated as inseparable mixture); $\mathbf{3}$ : Agaricoglyceride C; 4: Agaricoglyceride D; 5: DCMB; 6: 3,5-Dichloro-4-anisic acid; 7: Agaricic ester.

from microbial crude extracts was carried out, followed by identification of bioactive principles from the most promising hits by bioassay-guided fractionation.

The current paper deals with the discovery of a new class of biologically active natural products from cultures of edible mushrooms and other basidiomycetes. Their production, isolation, and biological properties are described here, while their physicochemical parameters, structure elucidation, derivatization and total synthesis have been compiled in a patent application [7]. Further details on their structure elucidation will be reported concurrently.

\section{Results and Discussion}

Isolation and Biological Activities of Agaricoglycerides (1 4) and Their Co-metabolites (5 7)

Agaricoglyceride A (1) was identified as the main active principle of the crude extract of A. macrosporus and later produced in gram scale as described in the Experimental for intensified biological evaluation, including a derivatization and in vivo studies. Chromatographic separation by preparative HPLC (Fig. 2) yielded several further congeners (structures see Fig. 1), of which only the mixture of monoacetyl agaricoglycerides $(\mathbf{1} \mathbf{a} / \mathbf{b})$ was more active than the parent compound (Table 1). Since the monoacetyl derivatives of compound $\mathbf{1}$ were detected in methanolic crude extracts prepared from growing cultures, they constitute original natural products rather than 


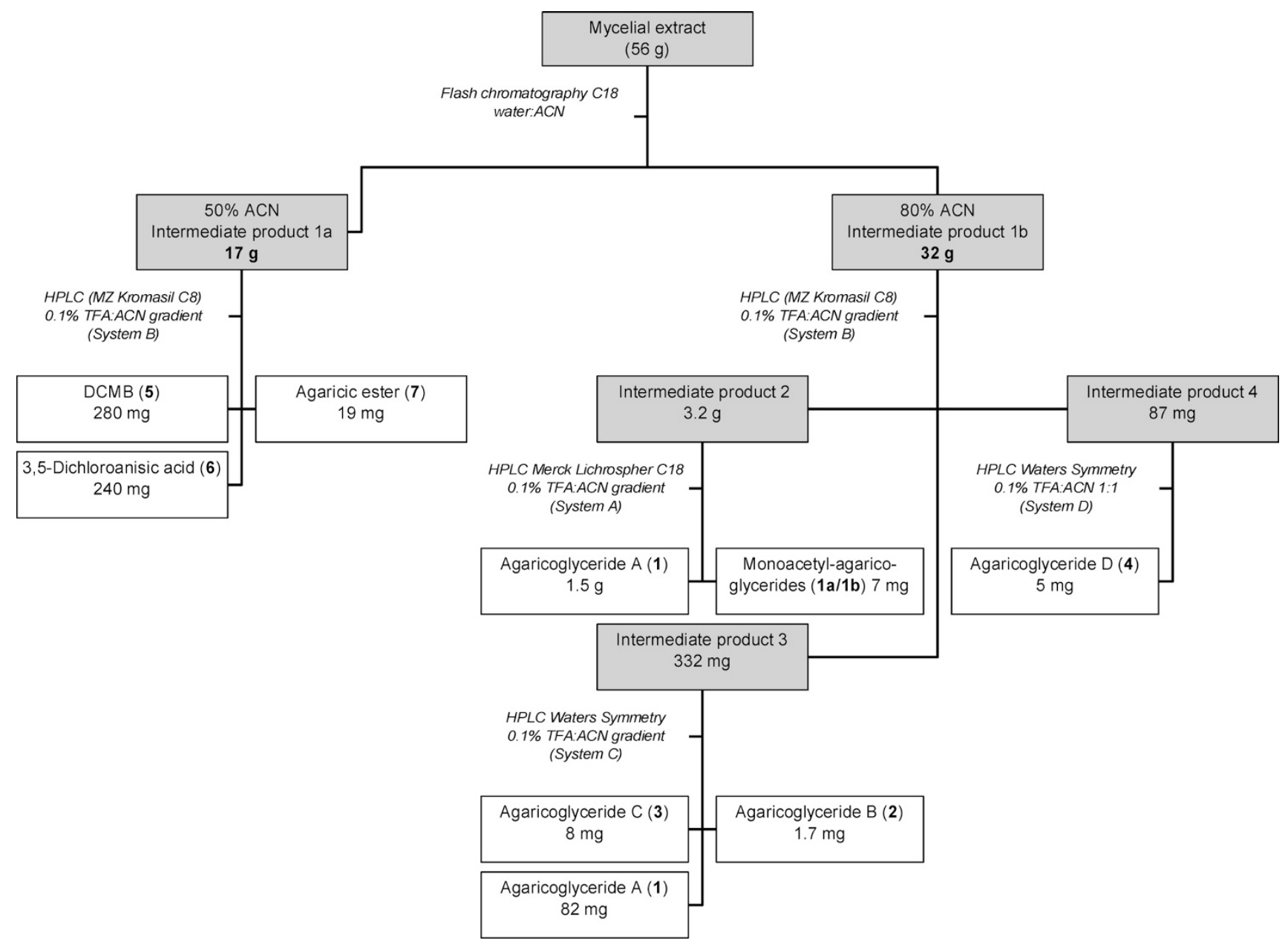

Fig. 2 Scheme illustrating the isolation of secondary metabolites from the mycelial crude extract of Agaricus macrosporus (200 liters scale; Q6/2 medium)

isolation artifacts. Their biological activities were confirmed for the mixture $\mathbf{1} \mathbf{a} / \mathbf{b}$, which were later on also prepared using the synthetic scheme depicted in Fig. 3. Synthetic agaricoglyceride A (1) was also obtained via this route and showed identical biological activities to that of the natural product [7].

Agaricoglyceride B (2) still showed activities in the micromolar range. However, despite differing in only one chlorine substitution from the main component, its activity was significantly lower than that of agaricoglyceride A (1). Agaricoglycerides $\mathrm{C}$ and $\mathrm{D}(\mathbf{3}, \mathbf{4})$, as well as the known cometabolites (5 and $\mathbf{6})$ and the novel agaricic ester (7) were found devoid of activity against neurolysin up to $10 \mu \mathrm{M}$.

\section{In vivo Activity}

As demonstrated in Fig. 4, agaricoglyceride A monoacetate (1b) showed significant in vivo activity in the cold plate model at $10 \mathrm{mg} / \mathrm{kg}$. Agaricoglyceride A (1) was also active
Table 1 Biological activities of compounds 1 7 against neurolysin and ACE

\begin{tabular}{lcc}
\hline Compound & $\begin{array}{c}\mid \mathrm{C}_{50}[\mu \mathrm{M}] \\
\text { against neurolysin }\end{array}$ & $\begin{array}{c}\mathrm{IC}_{50}[\mu \mathrm{M}] \\
\text { against ACE }\end{array}$ \\
\hline $\mathbf{1}$ & 0.2 & $>10$ \\
$\mathbf{1 a}, \mathbf{b}$ & 0.05 & $>10$ \\
$\mathbf{2}$ & 1 & $>10$ \\
$\mathbf{3}$ & $>10$ & $>10$ \\
$\mathbf{4}$ & $>10$ & $>10$ \\
$\mathbf{5}$ & $>10$ & $>10$ \\
$\mathbf{6}$ & $>10$ & $>10$ \\
$\mathbf{7}$ & $>10$ & $>10$ \\
\hline
\end{tabular}

in about the same concentration range, and morphine caused a similar effect, albeit already at a dosage of $3 \mathrm{mg} / \mathrm{kg}$. The results suggest a great analgesic potential for 


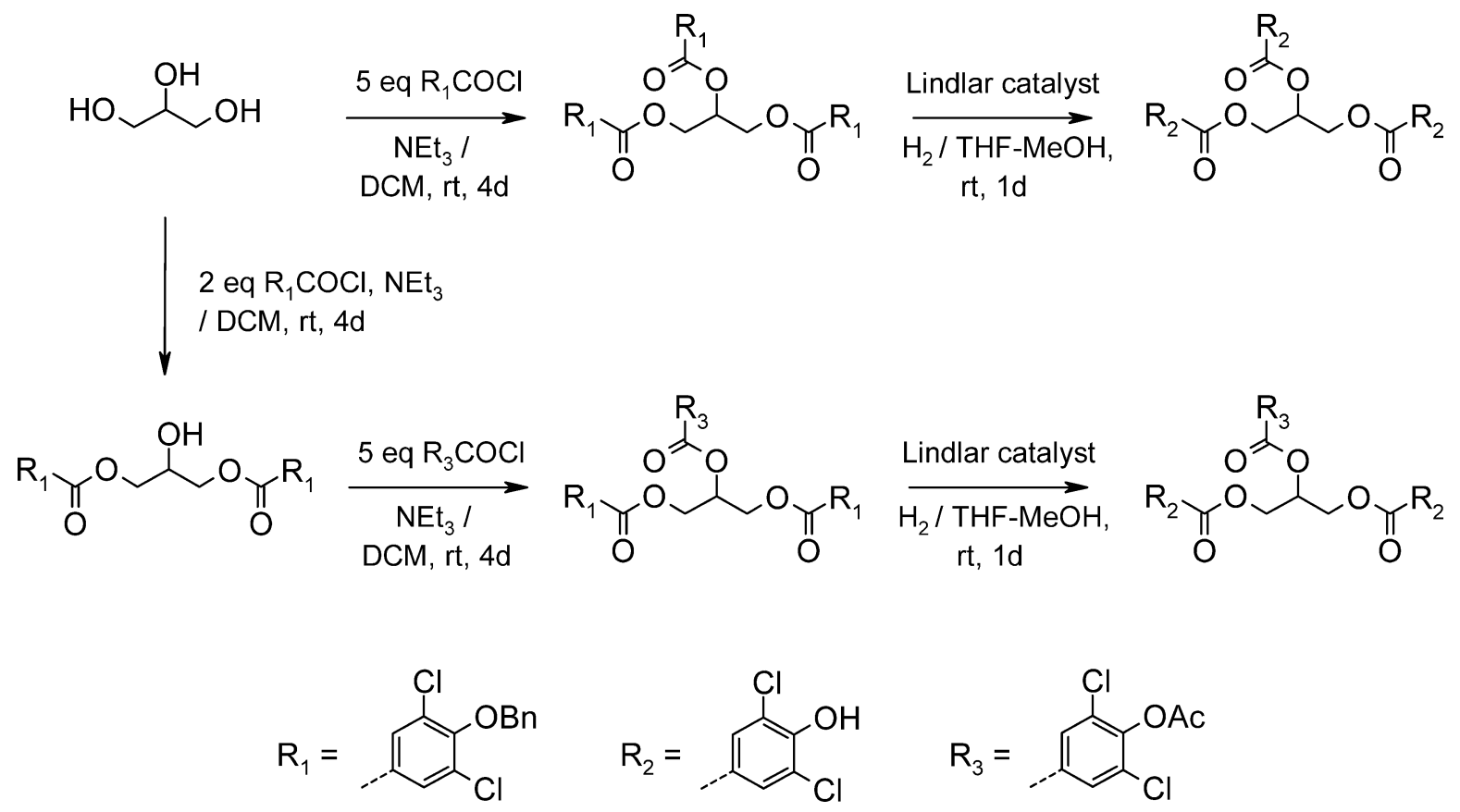

Fig. 3 General scheme for synthetic preparation of agaricoglycerides. For detailed descriptions, see Ref. 7.

Decreasing Temperature Cold-Plate in Rats

Effects of Agaricoglyceride monoacetate

30 minutes after application

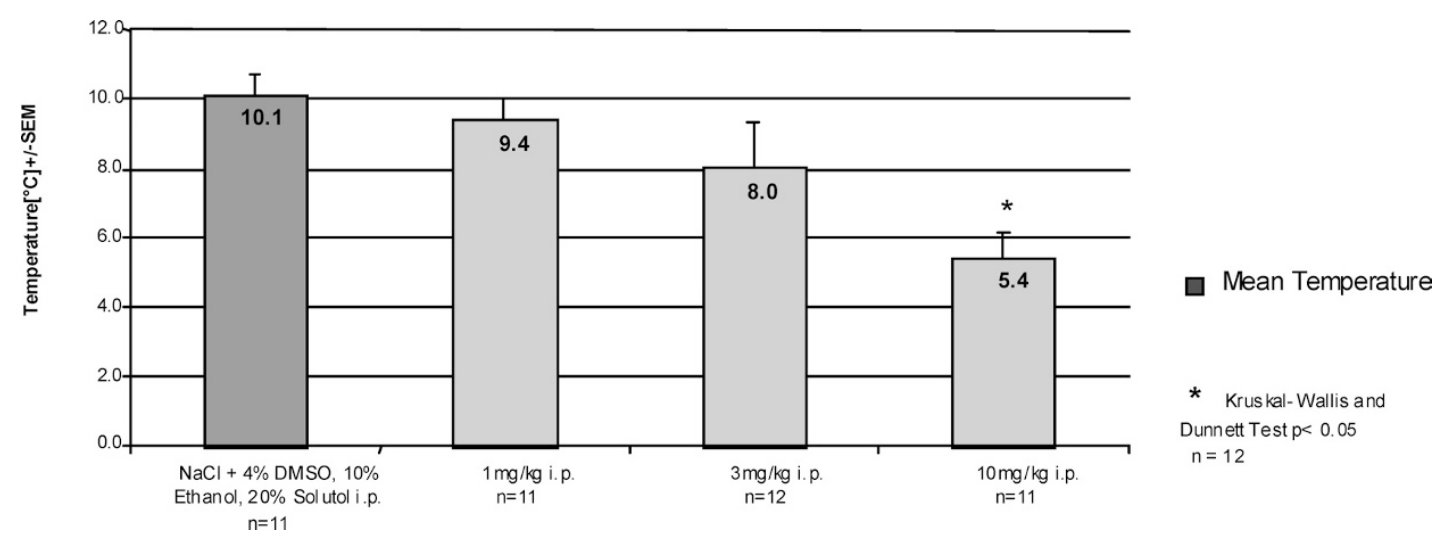

Fig. 4 In vivo analgesic activities of agaricoglyceride A monoacetate (1a/b).

agaricoglycerides, albeit their biological activities remain to be optimized and these in vivo effects confirmed in other animal models. Interestingly, the agaricoglycerides were devoid of activity in a large number of biochemical and cellular assays, emphasizing their selectivity towards neurolysin. Enzyme classes that were not inhibited by agaricoglycerides included, e.g., trypsin, chymotrypsin, phosphodiesterases $1 \sim 6$, caspases $1 \sim 7$, cathepsins $B \sim D$, several protein phosphatases, serine/threonin and thyrosine kinases, and matrix metalloproteases. No modulation of adrenergic, glutamate, gamma aminobutyric acid and other receptors was noted up to concentrations of $10 \mu \mathrm{M}$. Furthermore, the pure agaricoglycerides neither showed cytotoxic nor modulatory effects in various reporter cell assays that were conducted concurrently up to concentrations of $10 \mu \mathrm{M}$.

\section{HPLC Analyses during Fermentation and Optimization of Culture Media}

The agaricoglycerides were detected in various 
Table 2 Producers of agaricoglycerides, origin, taxonomy, and (in brackets) maximal production rates for agaricoglyceride A in Q6/2 medium at 300 hours of fermentation. Aside from strains DSM 14593 and DSM 14594, which were subjected to preparative work, all other producers were identified by analytical HPLC of their crude extracts only

\begin{tabular}{|c|c|c|}
\hline Species & Strain & Origin/collector/isolator [production rates] \\
\hline Agaricus arvensis Schaeff.:Fr. & MUCL 35030 & $\begin{array}{l}\text { leg. C. Decock, 1992, from Warcoing (Belgium)** } \\
\text { [2.4 mg/liter] }\end{array}$ \\
\hline A. bisporus (Lange) Imbach* & DSM 14900 & $\begin{array}{l}\text { leg. H. Müller, September 1991, from spores of cultivated mushrooms, Wuppertal } \\
\text { (Germany) } \\
\text { [4.9 mg/liter] }\end{array}$ \\
\hline \multirow[t]{4}{*}{ A. bitorquis (Quél.)Sacc. } & DSM 14895 & $\begin{array}{l}\text { leg. M. Stadler, STMA 98023, 9. May 1998, from Hamburg (Germany), near paved path } \\
\text { of lawn in Volkspark), culture from context of pileus } \\
\text { [7.7 mg/liter] }\end{array}$ \\
\hline & DSM 14894 & $\begin{array}{l}\text { leg. M. Stadler, STMA 97106, 9. September 1997, from Wuppertal-Elberfeld,Germany, } \\
\text { humus in flowerbed near roadside), culture from context of pileus } \\
\text { [2.4 mg/liter] }\end{array}$ \\
\hline & DSM 14594 & $\begin{array}{l}\text { leg. M. Stadler, STMA 97106, 9. September 1997, from Wuppertal-Elberfeld, Germany, } \\
\text { humus in flowerbed near roadside), culture from basidiospores } \\
\text { [1.9 mg/liter] }\end{array}$ \\
\hline & MUCL 28516 & $\begin{array}{l}\text { leg. G. L. Hennebert, no date, from Kapellen (Belgium)* } \\
\text { [2.5 mg/liter] }\end{array}$ \\
\hline $\begin{array}{l}\text { A. campestris var. campestris } \\
\text { L.:Fr. }\end{array}$ & MUCL 29004 & $\begin{array}{l}\text { leg. G. L. Hennebert, 1996, from Louvain-la-Neuve (Belgium), on lawn* } \\
\text { [<1 mg/liter] }\end{array}$ \\
\hline \multirow[t]{4}{*}{$\begin{array}{l}\text { A. macrosporus (Moeller \& J. } \\
\text { Schaeffer) Pilát }\end{array}$} & MUCL 28242 & $\begin{array}{l}\text { leg. G. L. Hennebert, 1993, Bois de Boulaide (Luxembourg)* } \\
\text { [6.6 mg/liter] }\end{array}$ \\
\hline & CBS 585.76 & $\begin{array}{l}\text { leg. W. Gams, September 1976, from Empolder near Embrugge (Netherlands)* } \\
\text { [5 mg/liter] }\end{array}$ \\
\hline & DSM 14593 & $\begin{array}{l}\text { leg. M. Stadler, STMA 97106, 7. August 1999, from Wuppertal-Elberfeld, Germany, lawn } \\
\text { of Bayer Pharma Research Center, culture from context of pileus } \\
\text { [14.5 mg/liter] }\end{array}$ \\
\hline & DSM 14594 & $\begin{array}{l}\text { leg. M. Stadler, STMA 97106, 7. August 1999, from Wuppertal-Elberfeld, Germany, lawn } \\
\text { of Bayer Pharma Research Center, culture from basidiospores } \\
\text { [13 mg/liter] }\end{array}$ \\
\hline A. xanthoderma Genev. ${ }^{*}$ & DSM 14901 & $\begin{array}{l}\text { leg. H. Müller, September 1991, from Wuppertal, Germany, culture from basidiospores } \\
\text { [<1 mg/liter] }\end{array}$ \\
\hline $\begin{array}{l}\text { Hypholoma marginatum } \\
\text { (Pers.:Fr.) J. Schröt. }\end{array}$ & DSM 14898 & $\begin{array}{l}\text { leg. M. Stadler, STMA 00034, 11. September 1997, from Schopp, Rheinland-Pfalz, } \\
\text { Germany, Finsterbrunnertal, on wood of Pseudotsuga, culture from context of pileus } \\
\text { [3 mg/liter] }\end{array}$ \\
\hline Hypholoma sp.* & DSM 14902 & $\begin{array}{l}\text { leg. R. Seeger, 25.9.1992, as Hypholoma subviride (Berk. \& M.A. Curtis) Dennis, from } \\
\text { the vicinity of Coburg, Germany } \\
\text { [<1 mg/liter] }\end{array}$ \\
\hline
\end{tabular}


Table 2 (Continued)

\begin{tabular}{l|l|l}
\hline \multicolumn{1}{c|}{ Species } & \multicolumn{1}{c|}{ Strain } & \multicolumn{1}{c}{ Origin/collector/isolator [production rates] } \\
\hline Psathyrella prona (Fr.) Gillet & DSM 14903 & $\begin{array}{l}\text { leg. H. Dörfelt, 3. September 1999, from Neuengönna (Thüringen, Germany) on meadow, } \\
\text { culture from basidiospores } \\
{[<1 \mathrm{mg} / \text { liter }]}\end{array}$ \\
\hline $\begin{array}{l}\text { Stropharia rugosoannulata } \\
\text { Farlow ex Murrill }\end{array}$ & DSM 11373 & $\begin{array}{l}\text { no data on collector available** } \\
{[1.5 \mathrm{mg} / \text { liter }]}\end{array}$ \\
\hline $\begin{array}{l}\text { Stropharia squamosa (Pers.:Fr.) } \\
\text { Quél. }\end{array}$ & DSM 14899 & $\begin{array}{l}\text { leg. M. Stadler, STMA 97126, 22.September 1997, near Johanniskreuz/Pfalz, Germany, } \\
\text { Burgalbspring } \\
\text { [2.3 mg/liter] }\end{array}$ \\
\hline
\end{tabular}

* No herbarium specimen extant to confirm taxonomy; but morphology and secondary metabolism of the culture in agreement with other strains of the respective taxa. ${ }^{*}$ Further information as to the correspondence of these strains may be retrieved from the catalogues or by contacting the staff of the public collections where these strains are deposited.

Table 3 Retention times (Rt) of compounds $1 \sim 7$ upon analytical HPLC

\begin{tabular}{ccc}
\hline \multicolumn{1}{c}{ Compound } & Rt (HPLC-UVNis) [min.] & Rt (HPLC-MS) [min.] \\
\hline $\mathbf{1}$ (Agaricoglyceride A) & $9.45 \sim 9.53$ & $4.65 \sim 4.67$ \\
$\mathbf{1 a , b}$ (Monoacetyl agaricoglyceride mixture) & $9.49 \sim 9.57$ & $4.72 \sim 4.74$ \\
$\mathbf{2}$ (Agaricoglyceride B) & $9.05 \sim 9.17$ & $4.57 \sim 4.58$ \\
$\mathbf{3}$ (Agaricoglyceride C) & $8.7 \sim 8.85$ & $4.29 \sim 4.32$ \\
$\mathbf{4}$ (Agaricoglyceride D) & $7.92 \sim 8.01$ & $3.88 \sim 3.93$ \\
$\mathbf{5}$ (DCMB) & $7.05 \sim 7.12$ & $3.61 \sim 3.65$ \\
$\mathbf{6}$ (Dichloro anisic acid) & $7.8 \sim 7.85$ & $3.72 \sim 3.74$ \\
$\mathbf{7}$ (Agaricic ester) & $8.1 \sim 8.15$ & $3.95 \sim 3.97$ \\
\hline
\end{tabular}

Parameters described in Ref. 26 (HPLC-MS) and Ref, 30 (HPLC-UVNis), respectively.

basidiomycetes (Table 2) by analytical HPLC profiling as described in the Experimental. The HPLC characteristics of all compounds detected are compiled in Table 3. In case of $A$. macrosporus strains that were chosen for intensified evaluation, similar yields were isolated from shake flasks and stirring fermentors, and the main component, agaricoglyceride A (1) was always encountered in substantial quantities in various culture media with different constituents (Table 4). Estimation of agaricoglycerides by HPLC analysis of crude extracts revealed that agaricoglyceride A (1) was present after 192 hours in all strains and culture media employed. In MGP and Q6/2, an increase of production was observed at prolonged fermentation times, and these media were chosen for 30 and 200 liter scales. While an analogous fermentation was also successful in MGP medium, the large scale production of agaricoglycerides is here only exemplified for a 200 liter culture in Q6/2 medium. The other agaricoglycerides $(\mathbf{1} \mathbf{a} / \mathbf{b}$ and $2 \sim 4$ ) were generally only present in traces. HPLC profiling of several related strains (data not shown), regardless whether they belonged to the genera Agaricus, Hypholoma, Stropharia or Psathyrella, frequently revealed only DCMB (5) and the conceivable acidic precursor of agaricoglycerides, 2,4-dichloro-anisic acid (6), but these strains apparently lacked the ability to form glycerol conjugates of the latter compound under the chosen conditions.

\section{Increase of Production of Agaricoglycerides in A. macrosporus by Precursor Feeding}

In attempts to increase production of agaricoglycerides, the culture medium of strain DSM 14593 was supplemented with putative precursors as described in the Experimental. As compared to the control $(12 \sim 13 \mathrm{mg} /$ liter of $\mathbf{1}$ in 
Table 4 Estimated yields (HPLC/UV) of agaricoglyceride A (1) $[\mathrm{mg} /$ /iter] in the mycelial extracts of strain DSM 14593 prepared from shake cultures in various culture media and at various stages of fermentation

\begin{tabular}{lcc}
\hline Medium & $\begin{array}{c}\text { Fermentation } \\
\text { time }[\mathrm{h}]\end{array}$ & $\begin{array}{c}\text { Estimated prduction rates } \\
\text { [mg agaricoglyceride } \\
\text { culture broth] }\end{array}$ \\
\hline MGP medium & 192 & 6.5 \\
& $300^{*}$ & 13.0 \\
& 360 & 10.4 \\
\hline Q6/2 medium & 96 & 4.0 \\
& 192 & 9.4 \\
& $300^{*}$ & 14.5 \\
\hline YMG medium & 360 & 12.9 \\
\hline Mycorrhiza medium* & 192 & 7.6 \\
ZM/2 medium* & 192 & 8.5 \\
\hline
\end{tabular}

* Maximum yields observed upon comparison of daily samples taken in the time range of $96 \sim 360$ hours.

conventional MGP), agaricoglyceride A (1) increased to $20.4 \sim 22.6 \mathrm{mg} /$ liter upon supplementation by the synthetic acid (6), and to $18.2 \sim 19.0 \mathrm{mg} /$ liter in the presence of 4hydroxybenzoic acid. Since a rather effective total synthesis of agaricoglycerides, and a synthetic approach to related compounds was concurrently elaborated, which appeared more practical for variation of the agaricoglyceride skeleton in attempts to increase bioactivity and establish structureactivity relationships [7], such supplementation experiments were not performed at a larger scale.

\section{Occurrence of Agaricoglycerides and Chemically Related Compounds in Nature}

The outcome of this study suggests that the production of agaricoglycerides and related metabolites in culture is widespread in the genus Agaricus (Agaricaceae). Moreover, several species belonging to other genera and families, such as Psathyrella (Coprinaceae), Hypholoma and Stropharia (Strophariaceae) are able to synthesize these aromatic triglycerides. Actually, chlorinated aromatics are wellknown from basidiomycetes, including the genera Hypholoma and Stropharia [8 10] from which agaricoglycerides are reported here. Agaricus spp. themselves have been shown to yield in culture several unique biological active metabolites such as blazeisporols
$[11,12]$. Even strobilurins were once obtained from an African Agaricus species [13]. Moreover, the cultivated mushroom, A. bisporus, was shown to produce the antibiotic, drosophilin A (i.e., p-methoxy tetrachlorophenol) [14]. In contrast, fruitbodies of Agaricus spp. are known to yield various aromatic heterocycles, including, e.g., the toxins of the poisonous A. xanthoderma, which have, however, so far not been found in cultures of these fungi [15]. A concurrent study on all materials designated STMA in Table 2, employing analytical HPLC of methanolic fruitbody extracts revealed that agaricoglycerides were not present in any of the fruitbodies of those fungi that were shown to produce them in culture.

Whereas simple chlorinated aromatics appear to be widespread especially in cultures of those basidiomycetes inhabiting humus or wood [16,17], there are relatively few examples of metabolites consisting of several aromatic chlorinated carboxylic acids. Only recently, the antiviral cytonic acids were found in cultures of the endophytic fungus, Cytonaema sp., which constitute esters of tridepsides [18]. The dichloro-anisic acid (6) is also a formal constituent of kaitocephalin, a glutamate receptor inhibitor from cultures of Eupenicillium shearii [19]. Furthermore, this building block also occurs in azaphilones of the falconensine type, which are metabolites of Emericella falconensis [20], as well as in the depsidones of some lichens [21]. Thielavins from ascomyceteous fungi of the genera Thielavia and Chaetomium constitute polyesters of three aromatic building blocks and were reported to act as glucose 6-phosphatase inhibitors [22]. They have also been reported previously to exhibit various other bioactivities (see summary in the latter reference). As glycerol esters of aliphatic fatty acids are essential constituents of the membranes of most prokaryotic and eukaryotic organisms, it is surprising that no aromatic diand triesters of glycerol have so far been reported from natural sources. Remote structural similarities to the agaricoglycerides are only to be found in few natural products such as the kelletinins. These compounds were isolated from, e.g., mollusks of the genus Kelletia [23]. They are aromatic polyesters of benzoic acid and butane tetrol (erythrol) and were reported to possess antiviral and antimicrobial activities. In addition, they show cytostatic effects, which are probably due to inhibition of eukaryotic RNA-polymerase alpha [24]. 


\section{Experimental}

\section{General}

If not indicated otherwise, all chemicals were provided by Sigma Aldrich (Deisenhofen, Germany), while media ingredients, solvents for chromatography and spectroscopy were obtained from Merck Eurolabs (Darmstadt, Germany).

Culture Media

For isolation of basidiomycete cultures, YMG[25], or Mycorrhiza medium (malt extract $0.8 \%$, glucose $0.7 \%$, asparagine $0.05 \%$, casein hydrolysate $0.1 \%, \mathrm{KH}_{2} \mathrm{PO}_{4}$ $0.05 \%, \mathrm{MgSO}_{4} 0.05 \%$, yeast extract $0.1 \%$, ad 1 liter deionized water, $\mathrm{pH} 5.05$, for solid media $1.5 \%$ Difco Bacto Agar were added before autoclaving) were employed. To avoid bacterial contamination upon preparation of primary cultures, the media were supplemented by antibiotics, adding sterile aqueous solutions of streptomycin sulfate and penicillin G (Sigma Aldrich, Deisenhofen, Germany), immediately after sterilization and adjustment of temperature to $55^{\circ} \mathrm{C}$ in a water bath, to final concentrations of each $125 \mathrm{mg} /$ liter for both antibiotics. For screening and fermentation, ZM/2 medium [26], MGP medium [27], and Q6/2 medium (glucose $2.5 \%$, glycerol 1 $\%$, cotton seed meal $0.5 \%, \mathrm{CaCO}_{3} 0.05 \%$, ad 1 liter tap water, no $\mathrm{pH}$ adjustment) were also employed besides liquid YMG and Mycorrhiza media. All media used for propagation of the fungi on either agar plates or shake cultures were sterilized at $121^{\circ} \mathrm{C}$ for 20 minutes, while media in fermentors were autoclaved in situ with steam for 60 minutes.

\section{Origin, Isolation and Taxonomy of Producer Strains}

All strains studied were derived from basidiocarps of agaricoid basidiomycetes and are listed in Table 2 . Those from materials designated STMA were identified by microscopic examination of the teleomorphs according to Refs. [28, 29]. These cultures were obtained from either spore prints or mycelial plugs taken from the context of the fruitbody tissue under sterile conditions upon plating the fungal materials on YMG medium or Mycorrhiza medium containing antibiotics (see above). Microscopic examination of the cultures showed the same microscopic and macroscopic features as those of related strains from public collections (which even showed similar secondary metabolite profiles by HPLC). Voucher specimens, which showed the characteristics of the genera and species, are kept in the herbarium of M. S. (Wuppertal, Germany). Some additional strains from the Bayer culture collection, as well as other ones from public collections were studied for comparison. All cultures are deposited with either CBS (Utrecht, Netherlands), DSMZ (Braunschweig, Germany), or MUCL (Louvain-la-Neuve, Belgium) as stated in Table 2. They are also maintained at the BHC Research Center, Wuppertal, Germany, on YMG agar slants and in $10 \%$ glycerol under liquid $\mathrm{N}_{2}$.

\section{Fermentation}

For screening and small scale production of desired compounds, all strains were propagated in 1 liter Erlenmeyer flasks containing $300 \mathrm{ml}$ of the above culture media. The flasks were inoculated using ten agar disks ( $c a$. $1 \mathrm{~cm}$ diameter) from well-grown mycelial cultures $(9 \sim 12$ days old) on YMG agar. Submerged fermentations were carried out on a rotary shaker at $23^{\circ} \mathrm{C}$ and $140 \mathrm{rpm}$. After 96 hours, daily samples were taken, extracted and analyzed by HPLC as described below. Large scale fermentations were carried out in stirring fermentors, using either MGP or Q6/2 media. $600 \mathrm{ml}$ of well-grown YMG shake cultures prepared as stated above were used as inoculum for 30 liter fermentors, while the culture of a 30 liter fermentor grown for ten days served as inoculum for the 200 liter fermentor. To avoid excessive foaming, media in fermentors were supplied with $1 \mathrm{mg} /$ liter culture medium of silicon antifoam agent SAG 5693 (Union Carbide, USA). Production cultures in 30 liter scale were grown for 331 hours (MGP) and 233 hours (Q6/2), respectively, at $24^{\circ} \mathrm{C}$ with agitation $(150 \mathrm{rpm})$ and aeration (3 liters sterile air/minute) in a 40 liter Biostat $\mathrm{E}$ fermentor (Braun Bioengineering, Melsungen, Germany). Production cultures in 200 liter scale were performed in a stirring fermentor (Bayer Health Care), using Q6/2 medium only. The culture was grown for 115 hours at $24^{\circ} \mathrm{C}$ under aeration ( 3 liters air/minute) and agitation (100 rpm).

All strains listed in Table 2 were studied for production of the desired compound in flask scale (see a comparison of production rates in this Table), and some of them also in 30 liters scale, but the best production rates were still observed with A. macrosporus strain DSM 14593. Therefore, optimization of production was mainly carried out using this organism.

\section{Analytical HPLC Methods}

The equipment used for analytical and preparative HPLC has been described in detail [30]. Characteristic retention times (Rt) in these two different gradient systems, along with UV/visual and mass spectra in comparison with external and internal standards served for detection of the metabolites in crude extracts and intermediate products obtained during downstream processing and chromatography. For estimation of active principles by 
HPLC during fermentation, $10 \mathrm{ml}$ of culture broth were withdrawn under sterile conditions. Mycelia were separated by filtration and extracted with $10 \mathrm{ml}$ acetone for 30 minutes in an ultrasonic bath. The acetone was then evaporated in vacuo $\left(40^{\circ} \mathrm{C}, 250\right.$ mbar), the aqueous residue diluted with water to $10 \mathrm{ml}$ and extracted with $10 \mathrm{ml}$ of ethyl acetate (EtOAc). An aliquot of $5 \mathrm{ml}$ of the organic phase was withdrawn, dried over $\mathrm{Na}_{2} \mathrm{SO}_{4}$ and evaporated in vacuo. Subsequently, the residue was redissolved in $1 \mathrm{ml}$ $\mathrm{MeOH}$ and analyzed by HPLC. The Rt values are summarized in Table 3 and the production rates of compound 1 estimated during fermentation in Table 4, using external and internal standards. HPLC-MS data suggested that no other peak was located beneath the agaricoglyceride A peak, and that the employed methodology was suited well to detect the compound quantitatively.

\section{Precursor Feeding to Enhance Production of Agaricoglycerides}

Shake cultures of A. macrosporus DSM 14593 were propagated in MGP medium containing $1 \mathrm{ml}$ of a solution of $50 \mathrm{mg}$ of the dichloro-anisic acid (6) or 4hydroxybenzoic acid, respectively, in glycerol: $\mathrm{MeOH} 1: 1$, which was added under sterile conditions immediately before inoculation. Fermentations were carried out for up to 360 hours, using the same inoculum in a control fermentation without supplements. Extracts were prepared and analyzed by HPLC to estimate agaricoglyceride A (1) as described above. Five flasks of each medium were used for comparison.

\section{Production and Isolation of Secondary Metabolites}

Small Scale Isolation

Ten YMG shake flasks of A. macrosporus DSM 14593 were grown for 192 hours. Mycelia were separated from the culture fluid by filtration and extracted twice with each 1 liter acetone for 30 minutes in an ultrasonic bath. The extract was filtered, and the acetone was removed in vacuo (ca. $40^{\circ} \mathrm{C}, 250 \mathrm{mbar}$ ) to yield an aqueous residue. This residue was diluted with tap water to $300 \mathrm{ml}$ and subsequently extracted three times with each $300 \mathrm{ml}$ EtOAc. The combined organic phases were dried over $\mathrm{Na}_{2} \mathrm{SO}_{4}$ and evaporated in vacuo to yield an oily residue $(160 \mathrm{mg})$. This crude extract was separated by preparative HPLC using system A: flow $9 \mathrm{ml} /$ minute; mobile phase $0,1 \%$ TFA (trifluoroacetic acid):ACN (acetonitrile); stationary phase: Merck LichroSorb RP-18 ( $7 \mu \mathrm{m}, 250 \times 25$ $\mathrm{mm})$; gradient: starting with $\mathrm{t}=0^{\prime}(20 \% \mathrm{ACN})$; linear to $\mathrm{t}=70^{\prime}(100 \% \mathrm{ACN})$; isocratic to $\mathrm{t}=88^{\prime}(100 \% \mathrm{ACN})$. Compound 1 (16 mg) was eluted at Rt 60 64 minutes, detected as single peak at $210 \mathrm{~nm}$. As side metabolite, DCMB (5; $5 \mathrm{mg}$ ) was obtained at Rt 41 46 minutes.

Large Scale Production/Isolation of Compound 1 and Isolation of Congeners

The combined mycelia from a fermentation of $A$. macrosporus DSM 14593 in 30 liters MGP medium were separated from the culture broth by centrifugation $(15$ minutes at $3000 \times g)$ and filtration and extracted four times with each 5 liters acetone under stirring. The resulting fluid was combined and filtered, then the acetone was evaporated in vacuo at $250 \mathrm{mbar}$. The resulting aqueous residue was diluted to 1 liter with $\mathrm{H}_{2} \mathrm{O}$ and subsequently extracted three times with each 1 liter EtOAc. The combined organic phases were dried over $\mathrm{Na}_{2} \mathrm{SO}_{4}$ and evaporated in vacuo to yield an oily residue $(4.5 \mathrm{~g})$. This product was divided into portions containing approximately $2.2 \mathrm{~g}$ and subjected to preparative HPLC using system B: flow $9 \mathrm{ml} /$ minute; mobile phase $0.1 \%$ TFA: ACN; stationary phase: MZ Analysentechnik (Mainz, Germany) Kromasil C8 (7 $\mu \mathrm{m}, 250 \times 40 \mathrm{~mm})$; gradient: starting with $\mathrm{t}=0^{\prime}(20 \% \mathrm{ACN})$; linear to $\mathrm{t}=20^{\prime}(45 \% \mathrm{ACN})$; isocratic to $\mathrm{t}=55^{\prime} \quad(45 \% \quad \mathrm{ACN})$; linear to $\mathrm{t}=90^{\prime} \quad(100 \% \quad \mathrm{ACN})$; thereafter isocratic at $100 \% \mathrm{ACN}$. Agaricoglyceride A (1) eluted at Rt $=101 \sim 108$ minutes. Approximately $300 \mathrm{mg}$ of the pure compound (1) were thus obtained from mycelia of a 30 liter culture. DCMB $(\mathbf{5}, 56 \mathrm{mg})$ was obtained at Rt $83 \sim 90$ minutes and dichloro anisic acid $(6,5 \mathrm{mg})$ at $\mathrm{Rt}$ 94 96 minutes. An analogous fermentation/downstream processing procedure yielded $420 \mathrm{mg}$ of agaricoglyceride A from 30 liter of Q6/2, medium. Besides this higher yield, fermentation time was reduced as compared to MGP medium, and Q6/2 was therefore chosen for further scale-up.

The combined mycelia of a fermentation of $A$. macrosporus strain DSM 14593 in 200 liters Q6/2 medium were separated from the culture broth by centrifugation $(15$ minutes at $3000 \times g)$ and filtration and extracted four times with each 7 liters acetone under stirring. The resulting fluid was combined and filtered, then the acetone was evaporated in vacuo at 250 mbar. The resulting aqueous residue was diluted to 1 liter with water and subsequently extracted three times with each one liter EtOAc. The combined organic phases were dried over $\mathrm{Na}_{2} \mathrm{SO}_{4}$ and evaporated in vacuo to yield an oily residue $(56 \mathrm{~g})$. This material was dissolved in acetone and absorbed to $50 \mathrm{~g}$ of $\mathrm{C}_{18}$ functionalized silicagel (Sigma Aldrich 37.763-5). The acetone was evaporated in vacuo, and the dried extract/silicagel mix was applied onto a glass column $(30 \times 4.8 \mathrm{~cm}$ diameter) filled with a bed of $30 \mathrm{~g}$ of the same silicagel that had previously been equilibrated to $50 \%$ 
ACN. A three-step gradient (each $200 \mathrm{ml}$ of $50 \%, 80 \%$ and $100 \%$ aqueous $\mathrm{ACN}$ ) was employed to achieve a crude fractionation. The $100 \%$ ACN fraction (19g) lacked agaricoglycerides and biological activities and was discarded. Intermediate product $1 \mathrm{a}(7 \mathrm{~g})$ eluted at $50 \%$ ACN and yielded DCMB (5, $280 \mathrm{mg})$, 3,5-dichloro anisic acid $(6,240 \mathrm{mg})$ and agaricic ester $(7,16 \mathrm{mg}$; Rt 98 99 minutes) upon repetitive HPLC on Kromasil C8 using gradient system B (see above). Intermediate product $1 b$ $(32 \mathrm{~g}$, eluted after intermediate product $1 \mathrm{a}$ at $80 \% \mathrm{ACN}$ ) was also further processed using the preparative HPLC system B as described above. For this purpose, intermediate product $1 \mathrm{~b}$ was portioned into aliquots of approximately $3.2 \mathrm{~g}$. Repetitive HPLC on Kromasil C8 thus yielded $3.2 \mathrm{~g}$ of an intermediate product 2, which was further processed by HPLC on Merck LiChrosorb C18 using system A. An overall amount of $1.5 \mathrm{~g}$ of pure agaricoglyceride A (1) was finally obtained. An inseparable mixture of monoacetyl agaricoglycerides $(\mathbf{1} \mathbf{a} / \mathbf{b})$ eluted under these conditions at Rt $112 \sim 114$ minutes. The identity of these compounds was later proven by synthesis of the single components and comparison of their spectral data as described in Ref. 7. An intermediate product $3(332 \mathrm{mg})$ eluted upon HPLC separation using system B at Rt 94 98 minutes. It was further processed using system C: flow: $9 \mathrm{ml} / \mathrm{minute}$; stationary phase: Waters SymmetryPrep C18 $(7 \mu \mathrm{m}, 300 \times$ $19 \mathrm{~mm}$ ); mobile phase $0.1 \% \mathrm{TFA}$ : ACN; gradient: $\mathrm{t}=0 \sim$ 10 minutes; isocratic at $50 \% \mathrm{ACN}$; thereafter linear to $\mathrm{t}=25^{\prime}(80 \% \mathrm{ACN})$; thereafter linear to $\mathrm{t}=44^{\prime}(100 \% \mathrm{ACN})$; thereafter isocratic at $100 \% \mathrm{ACN}$. This procedure afforded agaricoglycerides C (3, $8 \mathrm{mg}$, Rt 25 26 minutes) and B (2, $1.7 \mathrm{mg}$, Rt $29 \sim 30$ minutes) as well as another $82 \mathrm{mg}$ of agaricoglyceride A (1, Rt 30 32 minutes). An intermediate product $4(87 \mathrm{mg})$ was also obtained upon purification of intermediate product $1 \mathrm{~b}$ using HPLC gradient $\mathrm{B}$ at $\mathrm{Rt}=87 \sim 92$ minutes and further processed using HPLC gradient system $\mathrm{D}$ (like system $\mathrm{C}$ but isocratic conditions at $50 \%$ ACN : $0.1 \%$ TFA), affording $5 \mathrm{mg}$ of agaricoglyceride $\mathrm{D}$ (4) at $\mathrm{Rt}=12 \sim 14$ minutes. These procedures are also summarized in the scheme in Fig. 2.

\section{Neurolysin Inhibition Assay In Vitro}

For determination of in vitro activities against neurolysin (Endopeptidase EC 3.4.24.16), test compounds (extracts from fermentations, intermediate fractions obtained during chromatography and pure compounds) were dissolved in DMSO. Serial dilutions were made in dilution buffer (50 mM Tris/HCl, pH 7.5, 0.0025\% Brij-35), resulting in final concentrations of 10 to $0.078 \mu \mathrm{M}$. If necessary, further dilutions were prepared. The assay was performed in OptiPlate 96 well microtiter plates (Packard). Two microliters of the diluted test samples were incubated in each well, and $50 \mu 1$ of a neurolysin solution in dilution buffer (final concentration: $1.5 \mathrm{nM}$; resulting in no more than $70 \%$ turnover of the substrate after the subsequent incubation) were added. The peptidic substrate, DABCYLGlu-Arg-Nle-Phe-Leu-Ser-Phe-Pro-EDANS; was diluted in $50 \mathrm{mM}$ Tris/HCl buffer $(\mathrm{pH}$ 7.5) to final concentration of $5 \mu \mathrm{M}$ in each well. The enzyme reaction was initiated by addition of $50 \mu \mathrm{l}$ diluted substrate to the enzyme/test compound mix. The samples were then incubated for 90 minutes at RT. Thereafter, the $\mathrm{IC}_{50}$ values were determined by fluorometric methodology, using a FluorStar Fluorometer (BMG LabTechnologies; $\lambda_{\mathrm{ex}}=320 \mathrm{~nm}, \lambda_{\mathrm{ex}}=$ $520 \mathrm{~nm}$ ) and by plotting the results (substrate concentration $v s$. percentage of inhibition). Selectivity was established by using an analogous readout, employing various other proteases that were concurrently tested at the High Throughput Screening unit of Bayer HealthCare, but no significant activity was observed in any of the samples tested. For further data as to the selectivity of agaricoglycerides see above in Results and Discussion.

\section{Animal Model}

The methodology for determination of in vivo activities was described in detail in the corresponding patent [7]. Briefly, male Wistar rats (strain HsdCpb: WU) were housed in groups of six under standardized conditions. Conventional rat chow (Type R/M-H, Sniff Spezialdiaten GmbH, Soest, Germany) and tap water were given ad libitum. Rats were accustomed to the laboratory conditions for at least three days prior to experimental manipulations. The animals were randomly assigned to control or drug treated groups with $n=11 \sim 12$ per group. Experimental protocols and conditions were in conformity with the local regulations on animal welfare. Test compounds were presolubilized in mixture of DMSO, ethanol and Solutol HS 15 (BASF ChemTrade GmbH, Bargbernheim, Germany). This mixture was subsequently filled up with physiological saline to final concentrations of $4 \%$ DMSO, $10 \%$ ethanol and $20 \%$ Solutol. Intraperitoneal doses of 1,3 and $10 \mathrm{mg} / \mathrm{kg}$ body weight were applied in a volume of $2 \mathrm{ml} / \mathrm{kg}$. The decreasing temperature cold-plate was a selfconstructed device. It consisted of twelve plastic chambers $(24 \mathrm{~cm}$ high) with an aluminium floor $(21 \times 24 \mathrm{~cm})$ equipped from beneath with semiconducting Peltier elements. Cooling or heating of the floors was performed under computer control. Each of the twelve chambers could be controlled individually in order to conduct an experiment with twelve animals simultaneously.

Animals were treated with i.p. injection of test compounds or vehicle and placed individually in the cold- 
plate chambers. Initially, the floors of the chambers had a pleasant temperature of $30^{\circ} \mathrm{C}$. Thirty minutes after application the floors were cooled down with a linear ramp of $3^{\circ} \mathrm{C} /$ minutes and a cut-off temperature of $2.5^{\circ} \mathrm{C}$. The cold pain threshold was reached when the animals either took their forepaws repeatedly to the mouth or began restlessly to trip with the forepaws. When this behavior became evident the experiment was stopped and the threshold temperature was taken as a measure for the pain experienced. A decrease of the threshold temperature was considered to be a drug induced analgesia. Data were processed using the statistical software package SYSTAT Version 10. Experimental data have been analyzed with the Kruskal-Wallis test. Differences in the subsequent post-hoc Dunnett test were considered to be significant if $p<0.05$. Morphine was used as a standard.

Acknowledgements The authors wish to thank S. Seip, Bayer AG, for recording NMR and MS spectra and Dr. H. Müller (Bayer) and Profs. R. Seeger (Gamburg, Germany) and H. Dörfelt (Jena, Germany), who provided reference cultures, and Dr. H. Haning (BHC) for providing a synthetic sample of compound $\mathbf{6}$. Expert technical assistance by R. Bruchhausen, F. Jüngerkes, B. Heedmann, S. Heke, T. Küppers, O. Mertens, D. Müller, G. Norkewitz, P. Splittgerber, B. Tretter, and C. Wotsch is gratefully acknowledged.

\section{References}

1. Shrimpton CN, Smith AI. Soluble neutral metalloproteases: Physiological regulators of peptide action. J Peptide Sci 6: 251-263 (2000)

2. Tyler BM, Cusack B, Douglas CL, Souder T, Richelson E. Evidence for additional neurotensin receptor subtypes: neurotensin analogues that distinguish between neurotensinmediated hypothermia and antinociception. Brain Res 792: 246-252 (1998)

3. Dauch P, Vincent JP, Checler F. Specific inhibition of endopeptidase 24.16 by dipeptides. Eur J Biochem 202: 269-276 (1991)

4. Vincent B, Dive V, Yiotakis A, Smadja C, Maldonado R, Vincent JP, Checler F. Phosphorus-containing peptides as mixed inhibitors of endopeptidase 3. 4. 24. 15 and 3. 4. 24. 16: effect on neurotensin degradation in vitro and in vivo. Brit J Pharmacol 115: 1053-1063 (1995)

5. Jirácek J, Yiotakis A, Vincent B, Checler F, Dive V. Development of the first potent and selective inhibitor of the zinc endopeptidase neurolysin using a schematic approach based on combinatorial chemistry of phosphinic peptides. J Biol Chem 271: 19608-19611 (1996)

6. Bourdel E, Doulut S, Jarretou G, Labbe-Julle C, Fehrentz JA, Doumbia O, Kitabgi P, Martinez J. New hydroxamate inhibitors of neurotensin-degrading enzymes. Synthesis and active-site recognition. Int $\mathrm{J}$ Peptide Protein Res 48: 148-155 (1996)

7. Stadler M, Hellwig V, Wiese B, Burkhardt N, Denzer D, Mayer-Bartschmid A, Allerheiligen S, Gerisch M, Wirtz SN. Agaricoglycerides and analogs. WO 03, 055843, July 10 (2003)

8. Hautzel R, Anke H. Screening of Ascomycetes and Basidiomycetes for plant growth regulating substances: Introduction of the gibberrellic acid induced de novo synthesis of hydrolytic enzymes in embryoless seeds of Triticum aestivum as test system. Z Naturforsch 45C: 1093-1098 (1990)

9. Verhagen FJM, Swarts HJ, Kuyper TW, Wijnberg JBPA, Field JA. The ubiquity of natural adsorbable organic halogen production among basidiomycetes. Appl Microbiol Biotechnol 45: 710-718 (1996)

10. Swarts HJ, Verhagen FJM, Field JA, Wijnberg JBPA. Trichlorinated phenols from Hypholoma elongatum. Phytochemistry 49: 203-206 (1998)

11. Hirotani M, Sai K, Nagai R, Hirotani S, Takayanagi H, Yoshikawa T. Blazeispirane and protoblazeispirane derivatives from the cultured mycelia of the fungus Agaricus blazei. Phytochemistry 61: 589-595 (2002)

12. Hirotani M, Sai K, Hirotani S, Yoshikawa T. Blazeispirols B, $\mathrm{C}, \mathrm{E}$ and $\mathrm{F}$, des-A-ergostane-type compounds from the cultured mycelia of the fungus Agaricus blazei. Phytochemistry 59: 571- 577 (2002)

13. Zapf S, Anke T, Dasenbrock H, Steglich W. Antifungal metabolites from Agaricus sp. 89139. Bioengeneering 1: 92 (1993)

14. Grove JF. Volatile compounds from the mycelium of the mushroom Agaricus bisporus. Phytochemistry 20: 20212022 (1981)

15. Gill M, Steglich W. Pigments of fungi (Macromycetes) In Progress in the chemistry of organic natural products. Vol. 51. Eds., W. Herz et al., Springer Wien New York (1987).

16. De Jong E, Field JA. Sulfur tuft and turkey tail: Biosynthesis and biodegradation of organohalogens by basidiomycetes. Ann Rev Microbiol 51: 375-414 (1997)

17. Hjelm O, Borén H, Öberg G. Detection of halogenated organic compounds in soil from a Lepista nuda (wood blewitt) fairy ring. Chemosphere 32: 1719-1728 (1996)

18. Guo B, Dai JR, Ng S, Huang Y, Leong C, Ong W, Carté BC. Cytonic acids $\mathrm{A}$ and $\mathrm{B}$, novel tridepside inhibitors of hCMV protease from the endophytic fungus Cytonaema species. J Nat Prod 63: 602-604 (2000)

19. Kobayashi H, Shin-Ya K, Furihata K, Hayakawa Y, Seto H. Absolute configuration of a novel glutamate receptor antagonist kaitocephalin. Tetrahedron Lett 42: 4021-4023 (2001)

20. Itabashi T, Nozawa K, Myaji M, Udagawa S, Nakajima S, Kawai K. Falconensins A, B, C, and D, new compounds related to azaphilone, from Emericella falconensis. Chem Pharm Bull 40: 3142-3124 (1992) 
21. Lumbsch T. Taxonomic use of metabolic data in lichenforming fungi. In Chemical fungal taxonomy. Eds. J. C. Frisvad et al., pp. 345-387, Marcel Dekker, New York (1998).

22. Sakemi S, Hirai H, Ichiba T, Kato Y, Kojima N, Nishida H, Parker JC, Sato T, Tonai H, Kachi H, VanVolkenburg MA, Yoshikama N, Kojima Y. Thielavins as glucose-6phosphatase (G6Pase) inhibitors: Producing strain, fermentation, isolation, structure elucidation and biological activities. J Antibiot 55: 941-951 (2002)

23. Tymiak AA, Rinehart Jr. KL. Structures of kelletinins I and II, antibacterial metabolites of the marine mollusk Kelletia kelletii. J Am Chem Soc 105: 7396-7401 (1983)

24. Orlando P, Carretta F, Grippo P, Cimino G, De Stefano S, Strazzullo G. Kelletinin I and kelletinin A from the marine mollusk Buccinulum corneum are inhibitors of eukaryotic DNA polymerase $\alpha$. Experientia 47: 64-66 (1991)

25. Hellwig V, Grothe T, Mayer-Bartschmid A, Endermann R, Geschke FU, Henkel T, Stadler M. Altersetin, a new antibiotic from cultures of endophytic Alternaria spp. Taxonomy, fermentation, isolation, structure elucidation, and biological activities. J Antibiot 55: 881-892 (2002)
26. Stadler M, Tichy HV, Katsiou E, Hellwig V. Preliminary evidence on the chemotaxonomy of Pochonia and other conidial fungi with Verticillium-like anamorphs. Mycol Prog 2: 95-122 (2003)

27. Stadler M, Anke H, Arendholz WR, Hansske F, Anders U, Bergquist KE, Sterner O. Lachnumon and lachnumol A, new metabolites with nematicidal and antimicrobial activities from the ascomycete Lachnum papyraceum. I. Fermentation, isolation and biological activities. J Antibiot 46: 961-967 (1993)

28. Moser M. Die Rohrlinge und Blatterpilze. In Kleine Kryptogamenflora. Ed., W. Gams. Vol. 2b/2, Fischer Verlag, Stuttgart (1983)

29. Kirk PM, Cannon PF, David JC, Stalpers JA. Eds., Dictionary of the Fungi, Ninth Edition, CABI Publishing, Wallingford (2001)

30. Mühlbauer A, Triebel D, Persoh D, Wollweber H, Seip S, Stadler M. Macrocarpones, novel metabolites from stromata of Hypoxylon macrocarpum and new evidence on the chemotaxonomy of Hypoxylon. Mycol Prog 1: 235-248 (2003) 